\title{
Rewards and Performance of Health Centres IV workers in Greater Mbarara District.
}

\author{
Johnson.Atwiine**, Gershom. Atukunda and Justus. Asasira \\ Bishop Stuart University. \\ DOI: 10.29322/IJSRP.11.09.2021.p11734 \\ http://dx.doi.org/10.29322/IJSRP.11.09.2021.p11734
}

\begin{abstract}
The purpose of this paper is to study the relationship between rewards, and performance of Health Centre IV workers in greater Mbarara District. The constructs of rewards include; salary, performance bonus, recognition and promotion. This study used cross-sectional, explanatory and correlational approaches. Health center IV workers data were collected by means of a questionnaire survey from a sample of 200 health workers from 11 health centres from greater Mbarara district. Structural equation modelling was used to test the hypotheses. Results show that rewards significantly affect health workers' performances. Therefore, once health centres IV have appropriate reward strategies for their health workers in health facilities, they are likely to work hard by meeting deadlines, being available at their work station and they would eventually enhance on job performance. It is further recommended that all health policy makers and implementators at both Ministry of health and central government should always emphasize the general wellbeing of all health workers in every health facility.
\end{abstract}

Index terms- Rewards, Performance of Health Center IV Workers

\section{BACKGROUND OF THE STUDY}

At the helm of 1980s, Uganda's health sector was in a state of breakdown with dilapidated, filthy and ill equipped public health facilities, health workers were also disheartened due to low wages, which at times were paid or delayed to be paid (ann Richey, 2010) During this period, public funding for the sector was as low as $2.5 \%$ of the national budget and fairly irregular. Health services were mostly compulsory from personal health facilities not for Profit (PNFP) facilities and Private Health Practitioners' (PHPs) sector (Larsson, 2012). This was induced by decades of neglect, taking away valuable resources and massive movement of health practitioners for green pasture elsewhere, which was replications of the general system breakdown in the country (MOH Report, 2016).

This institutional collapse especially health sector become worse due the re-emergence of diseases that had been previously controlled such as sleeping sickness, TB, guinea worm, measles and HIV/AIDS (Okech, 2014).Over this period, the health displays in the country were among the poorest in the region and the whole world. Due to the absence of confidence and trust in the existing public institutions especially health sector, the majority of the donor funding was cut off. (MOH Report, 2016). Under these circumstances, donors could regulate which part of the country as well as which type of services were to be allocated money. Government therefore, bowed down to fund services at health facilities including salaries and wages of health workers while donors financed primary health care services, some extension services and renovation of infrastructure (Kutzin, 2001). Effective early 1986, Uganda focused on major changes in the wider public domain including the health sector. The reforms included the renovation of the existing facilities to restore functional capacity, and a shift of emphasis was put on Primary Health Care (PHC), with a well-defined package of cost-effective services.(Witter et al., 2019)

Similarly, development partners, on the other hand, enhanced or intensified funding to the health sector although other alternative financing ways were heartened in the longer term. Alternative was thought to introduce user fees whereby the public would make some support for the use of health services. This was, however, not exceptional to Uganda, as many multilateral and bilateral 
International Journal of Scientific and Research Publications, Volume 11, Issue 9, September 2021 ISSN 2250-3153

agencies were commending alternative ways of funding for health services in developing nations (Uganda) as part of structural adjustment programmes (SAPs) introduced by World Bank and IMF(Peters, 2017).In the same spirit, in mid-1990s the government advanced two policy documents namely, a ten year National Health Policy (NHP) and a five-year Health Sector Strategic Plan (HSSP)(Koo \& Expert, 2008).Here decentralization underscored on policy documents, and thereafter government came up with minimum package of services that were intended to address the major origins of disease problem and supply of public resources including health inputs (WHO,2000).Major fears were the control of communicable diseases like malaria, HIV/AIDS and TB, the amalgamated management of childhood illnesses, sexual and World reproductive health and rights. Others were public health mediations like immunization, school health, health education and promotion, environmental health (MoH Report, 2016).

Additionally, changes were later adopted in the first NHP including the Sector Wide Approach (SWAp), Public-Private Partnership, abolition of user fees, provision of autonomous for National Medical Stores (NMS) and decentralization with the responsibility of bringing health services to grass root authorities $(\mathrm{MoH}, 2016)$. The appropriate health infrastructure was also tailored to the Health Infrastructure Development and Maintenance Plan (HIDMP).Also, a Human Resource Development Plan (HRDP) for handling major limitations of inadequate numbers and unsuitable placement of trained health personnel in different health facilities was equally developed. The NHP and HSSP also put out plans for the health care delivery system with the enhanced alignment of structures and accountabilities with fundamental functions at both the central and district levels. Whereas the central level reserved with the responsibilities of policy formulation and stewardship, the decentralized units continued with the duty of service delivery (MoH, 2016). Relatedly, these changes were meant to obtain quality health care services by the majority of people in the country who by then had accessibility challenges. The government further considered a sustainable broad-based national Health Financing Strategy (HFS) to enable the realization of efficient, effective and equitable distribution and use of resources in the health sector. Similarly, stronger donor co-ordination was established through the Sector Wide Approach (SWAp) for health advancement (GoU, 2010). At around the same time, an autonomous was approved to the decentralized units to increase revenue locally for their activities and improving the health personnel (González-Pier et al., 2006); MoH, 2016).

\section{STATEMENT OF THE PROBLEM}

In a bid to achieve improved performance of health workers, Government of Uganda laid interventions like introducing RBF (Result Based Financing) that is paying health workers allowances to patients attended, refurbishing health centres and salary enhancements of health workers, increased training of lower health workers by DHTs, regular supervision and follow-up, training 2,350 health workers in newborn resuscitation in order to improve newborn health and survival bringing the percentage of health workers trained to $39 \%$ within the last two years, 75 health workers were trained in inter Personal Psycho Therapy for Groups, 13 health workers in south western region were trained on the clinical management of Viral Hemorrhagic Fevers, $40 \%$ of health workers have been trained on the HMIS revised tools, additional mentoring and couching was done to improve reporting and data use at a health center facility level (MoH Annual Health Sector Performance Report, 2019/2020).

Despite the government's interventions, the performance of health workers in health center IVs around greater Mbarara has fallen drastically from 79\% in 2014/15 to 69\% in 2015/16. In specific health centers such as Rwekubo HCIV in Isingiro district, the average absenteeism rate across all health workers was $27 \%$, with medical doctors having the highest rate of $36 \%$ and male nurses having the lowest rate of $12 \%$, the absenteeism rates obtained through attendance records were found to be around $10 \%$ lower on average, indicating that health workers managed to sign in without being present at the health center (Health Monitoring Unit Report, 2019). In Bwizibwera HC IV, the average rate of absenteeism was $48 \%$ among all types of health workers. Nursing officers had higher rates of absenteeism 
at (24\%) compared with nursing assistants and enrolled nurses (18\%), enrolled mid wives (15\%), and lab assistants (6\%) (Health Monitoring Unit Report, 2018). In Kazo HCIV, heath workers don't attend to emergencies like accidents, maternity and some contagious diseases hence referring them to Rushera Hospital or Mbarara Regional Referral hospital with a first aid (Kazo district Abstract Report, 2018/2019). It was noted by Mbarara district Abstract Report (2017/2018) and Health Monitoring Unit Report (2018) that Health centers in Mbarara district face a challenge of health workers to patient ratio especially at Mbarara municipal HCIV that was recorded at 1:765 which affects their productivity work monthly, the overall average productivity declined by 5\% from 2015-2018.

Little is known about the cause of performance of health workers in health centers but previous studies have tended to associate poor employee performance with rewards discrepancies (Danish \& Usman, 2010; Sukunala, 2016; Chadha and Chadda, 2018).This study investigated therefore, the association between rewards and performance of health centre IV workers in Greater Mbarara District

\section{OBJECTIVES OF THE STUDY}

The overall objective of this study is to establish the relationship between rewards and performance of health centres IV workers in greater Mbarara district. The specific objectives of the study include:

- To establish the relationship between Salary and performance of health centres IV workers

- To establish the relationship between Performance bonus and performance of health centres IV workers

- To assess the association between Recognition and performance of health centres IV workers

- To establish relationship between Promotion and performance of health centres IV workers.

\section{MATERIALS AND METHODS}

The study employed a cross-sectional survey design, where descriptive, correlational and explanatory approaches were used. In a cross-sectional study, a particular phenomenon is studied at a particular period of time. Cross-sectional designs are appropriate for studies designed at finding out the manifestation of a phenomenon, situation, problem or attitude, by identifying a cross-section of the population at a given time. Therefore, Cross-sectional research design is a form of observational study that investigates data collected from a population, or a representative subset, while correlational research design is a quantitative approach of research in which there are two or more variables from similar group of subjects from which a relationship can be determined if it happens or not (Mukyala, 2018).

The study population comprised of 11(Eleven) Health Centres IV in greater Mbarara District which include: Mbarara Municipal Health Centre IV, Bwizibwera Health Centre IV, Kinoni Health Centre IV, Bugamba Health Centre (Mbarara), Kabuyanda Health Centre IV, Nyamuyanja Health Centre IV, Rwekubo Health Centre IV, Rugaaga Health Centre IV (Isingiro), Ruhoko Health Centre IV (Ibanda), Kiruhura Health Centre IV and Kazo Health Centre IV.

The study targeted population of health workers from 11 health Centre IVs in Greater Mbarara District. These health workers comprised of medical officers, clinical officers, nursing officers, laboratory attendants, non-medical staff and support staff. A sample size of 200 participants were selected using both stratified and systematic sampling techniques.

Table 1. Sample distribution by category

\begin{tabular}{|l|l|l|}
\hline Population Category & Population size & Sample size \\
\hline Medical officers & 71 & 35 \\
\hline Clinical officers & & \\
\hline Nursing officers & 43 & 21 \\
\hline Medical laboratory attendants & 162 & 79 \\
\hline Non-medical staff & 29 & 14 \\
\hline Support staff & 38 & 19 \\
\hline
\end{tabular}

This publication is licensed under Creative Commons Attribution CC BY.

http://dx.doi.org/10.29322/IJSRP.11.09.2021.p11734 


\begin{tabular}{|l|l|l|}
\hline Total & 409 & 200 \\
\hline
\end{tabular}

Source; (District Health Reports, 2019)

\section{Questionnaire and Measurement}

A semi-structured questionnaire was developed using item measures and scales developed and tested by previous scholars (Bhattacherjee, 2012); (Harris \& Brown, 2010) and (Churchill \& Iacobucci, 2004). The questionnaire comprised of mainly closed-ended questions and it were anchored by a five point Likert scale ranging from strongly disagree (01) to strongly agree (05) to allow respondents register the degree of agreement. A pre-test of the instrument undertaken to establish the reliability and validity of the instrument before the main survey. It was self-administered by the researcher and his researcher assistants through interview approach and the exercise was carried out with in a period of three months to provide ample period to the completion of the questionnaire by the respondents. This was intended to achieve consistency and accuracy in answering the questions. Table. 2 shows variable and their measures reliability scale.

Table 2. Variable and their Measurement.

\begin{tabular}{|c|c|c|c|c|}
\hline $\begin{array}{l}\text { Global } \\
\text { Variable }\end{array}$ & Definition & $\begin{array}{l}\text { Dimensions and Issues to } \\
\text { examine }\end{array}$ & Measurement & Sample items \\
\hline \multirow[t]{3}{*}{ Rewards } & \multirow[t]{3}{*}{$\begin{array}{l}\text { the benefits, financial and } \\
\text { non-financial, that an } \\
\text { the employee obtains } \\
\text { through his/her } \\
\text { employment relationship } \\
\text { with an organization } \\
\text { (Malhotra et al., 2007) }\end{array}$} & $\begin{array}{l}\text { Salary } \\
\text { Evaluation of payment } \\
\text { received for the job } \\
\text { (Malhotra et al., 2007; } \\
\begin{array}{l}\text { Hackman \& Oldham, } \\
\text { 1974) }\end{array}\end{array}$ & $\begin{array}{l}\text { Respondents' } \\
\text { mean score of } 4 \\
\text { items included in } \\
\text { the questionnaire } \\
\text { on a 5-point } \\
\text { scale. } \\
\text { *Very } \\
\text { unsatisfactory } \\
\text {....Very } \\
\text { satisfactory } \\
\text { *Very } \\
\text { unrewarding } \\
\text {....very } \\
\text { rewarding } \\
\text { *Very small } \\
\text {...very large } \\
\text { *Very wrong } \\
\text {....very right }\end{array}$ & $\begin{array}{l}\text { "The amount of salary I get at } \\
\text { this health facility is..." }\end{array}$ \\
\hline & & $\begin{array}{l}\text { Bonus \& Fringe benefits } \\
\text { Evaluation of bonus and } \\
\text { fringe benefits received } \\
\text { for the job (Malhotra et al., } \\
2007 \text {; Hackman \& } \\
\text { Oldham, 1974) }\end{array}$ & $\begin{array}{l}\text { Respondents' } \\
\text { mean score of } 4 \\
\text { items included in } \\
\text { the questionnaire } \\
\text { on a 5-point } \\
\text { scale. } \\
\text { *Very } \\
\text { unsatisfactory } \\
\text {....Very } \\
\text { satisfactory } \\
\text { *Very } \\
\text { unrewarding } \\
\text {....very } \\
\text { rewarding } \\
\text { *Very small } \\
\text {....very large } \\
\text { *Very wrong } \\
\text {....very right }\end{array}$ & $\begin{array}{l}\text { "The bonus and fringe } \\
\text { benefits I get at this health } \\
\text { facility is ...." }\end{array}$ \\
\hline & & $\begin{array}{l}\text { Promotion Evaluation of } \\
\text { promotion received for the } \\
\text { job (Malhotra et al., 2007; }\end{array}$ & $\begin{array}{l}\text { Respondents' } \\
\text { mean score of } 4 \\
\text { items included in } \\
\text { the questionnaire }\end{array}$ & $\begin{array}{l}\text { "The promotion done at this } \\
\text { health facility is ...." }\end{array}$ \\
\hline
\end{tabular}

This publication is licensed under Creative Commons Attribution CC BY. 


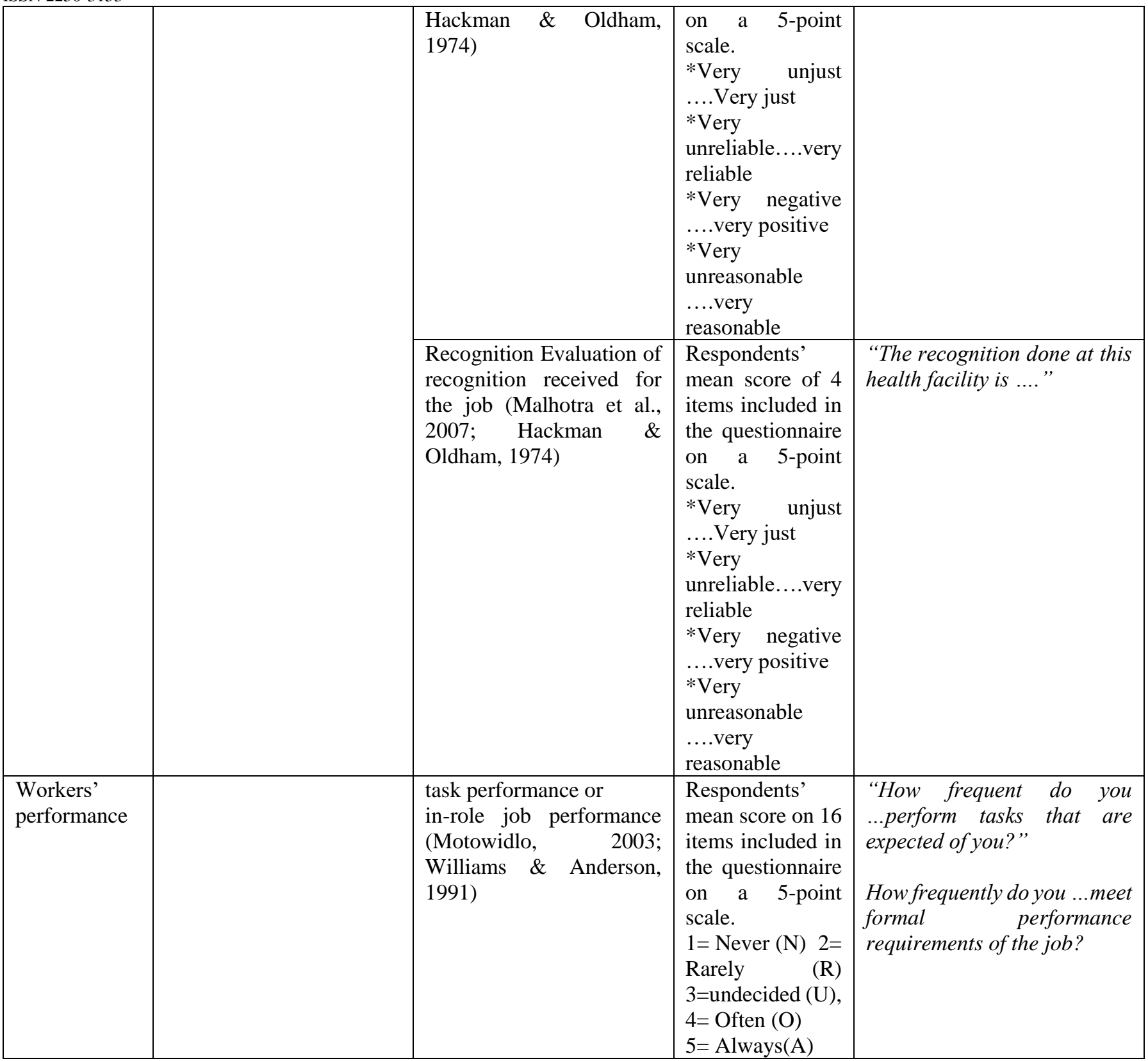

\section{Data Processing and Analysis}

After the fieldwork, the data were input into Statistical Package for Social Science (SPSS) version 21 and subjected to a thorough cleaning before hypothesis testing. Two statistical software packages were utilized to analyse the data collected. Specifically, SPSS version 21 was used for preliminary data analysis, while Analysis of Moments of Structures (AMOS) version 21 was used for Structural Equation Modelling (SEM) guided by confirmatory factor analysis.

\section{Confirmatory Factor Analysis Measurement model for Organizational Reward}

\section{Fig1. Confirmatory Factor Analysis for Organisational rewards}




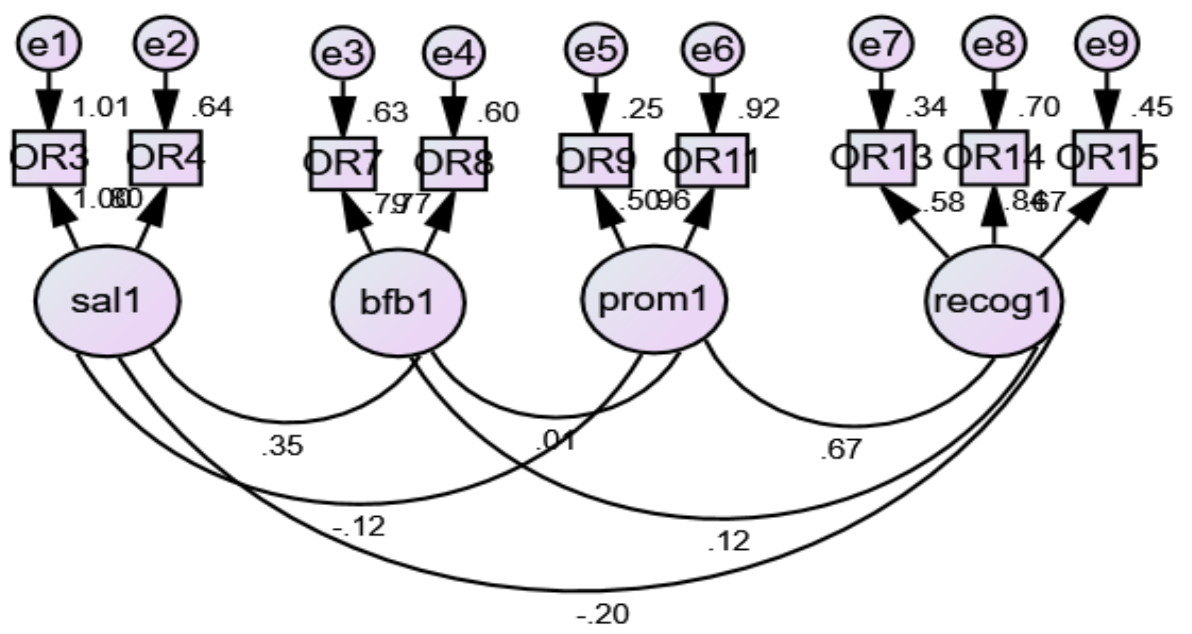

\section{chi-square $=28.880=28.880, \mathrm{DF}=21, \mathrm{P}=.117, \mathrm{RMSEA}=\operatorname{lrmse}, \mathrm{GFI}=.969$, $\mathrm{NFI}=.954, \mathrm{IFI}=.987, \mathrm{TLI}=.977$}

Organizational reward was measured using salary, bonus and fringe benefits, promotion and recognition. The results showed that although the standardized parameter estimates of the initial measurement model were all significant ( $\mathrm{p}<.001)$, the model provided a poor fit as indicated by the poor fit-indices. The model was re-specified by iteratively removing five ('OR1' 'OR2', 'OR5', 'OR6', 'OR10' and 'OR16') out of fifteen items that did not meet the acceptable criteria. The removal of the weak correlated items did not change the content of the construct as it was conceptualized.

Table 3. Standardized weights for Organizational Rewards

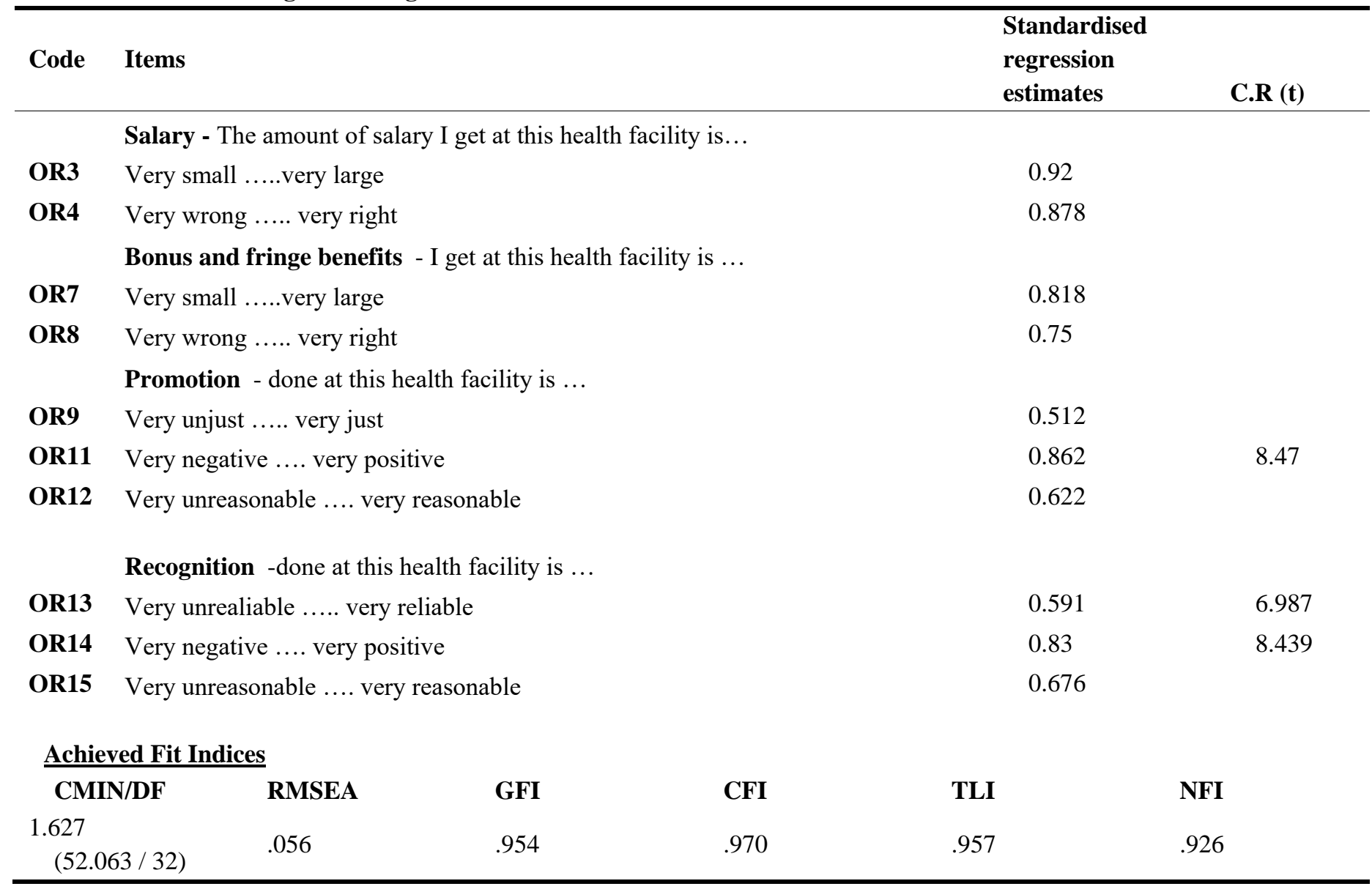


The findings confirmed the validity of the final model with excellent model fit statistics for this construct measure as reported in table 3, even though the chi-square was still significant. The measurement model can be judged as providing an acceptable fit even though the chi-square value is statistically significant (Anderson Gerbin), especially with a large sample size (Bagozzi \& Yi, 1988). Other assumptions for convergent validity were also met. The composite reliability for rewards is .798, which is within the acceptable level as indicated by Nunnally (1982).

\section{V.RESULTS AND DISCUSION}

\section{Results}

Descriptive statistics of the study variables

The descriptive statistics generated in this study included means and standard deviations. On a 5-point scale, the means for organizational reward and workers' performance are 3.205 and 3.361 with standard deviations of 0.5199 and 0.999 , respectively. According to (Lo \& Field, 2018), when deviations are small compared to mean values, it is evident that the data points are close to the means, and hence, calculated means highly represent the observed data.

\section{Correlation analysis}

The correlation results are presented in table 3.1. The results indicate a statistically strong significant relationship between o reward and performance of health Centre IV workers in greater Mbarara District $(\mathrm{r}=.474, p=.000)$. This provides support to hypothesis which states that there is a significant relationship between reward and workers' performance among health Centre IV workers in greater Mbarara District. This means that positive changes in reward are associated with positive changes in workers' performance. The results further show that hypotheses 1, 2, 3 and 4 which cover the relationship between the elements of reward and workers' performance appear to be supported as well with salary having a stronger association followed by bonus and fringe benefits and for the case of promotion and recognition they have the same association with workers' performance

Table 3.1. Correlation results and descriptive statistics

\begin{tabular}{|c|c|c|c|c|c|c|}
\hline \multirow[b]{2}{*}{ Variables } & \multicolumn{6}{|l|}{1} \\
\hline & & 2 & 3 & 4 & 5 & 6 \\
\hline Salary(1) & 1 & & & & & \\
\hline Bonus and fringe benefits(2) & $.283^{* *}$ & 1 & & & & \\
\hline Promotion(3) & -.108 & .010 & 1 & & & \\
\hline Recognition(4) & $-.170^{*}$ & .088 & $.503^{* *}$ & 1 & & \\
\hline Rewards(5) & $.562^{* *}$ & $.600^{* *}$ & $.547^{* *}$ & $.551^{* *}$ & 1 & \\
\hline Workers' Performance(6) & $.515^{* *}$ & $.169^{*}$ & $.145^{*}$ & $.145^{*}$ & $.474^{* *}$ & 1 \\
\hline
\end{tabular}

**. Correlation is significant at the 0.01 level (2-tailed). $n=198$ health workers

*. Correlation is significant at the 0.05 level (2-tailed).

The motivation of this study was driven by the possibility of differences in contribution of organizational rewards in explaining workers' performance. To do this, first, we regress rewards as a global variable with the control variables (level of education of the health workers) on workers performance. This is followed by a hierarchical regression where we determine the contribution of each element of rewards in explaining workers' performance.

Regression analysis results for

Regression involving organizational factors as a global variable

Two models were specified as:

Model 1: $\mathrm{WP}=\mathrm{b}_{0}+\mathrm{b}_{1} \mathrm{E}+\varepsilon$

Model 2: $\mathrm{WP}=\mathrm{b}_{0}+\mathrm{b}_{1} \mathrm{E}+\mathrm{b}_{2} \mathrm{R}+\varepsilon$

Where:

$W P=$ workers performance

$b_{0}$ - is a constant

$b_{1} E$ - is the unstandardized B coefficient of level of education of the health workers

This publication is licensed under Creative Commons Attribution CC BY.

http://dx.doi.org/10.29322/IJSRP.11.09.2021.p11734

www.ijsrp.org 
$b_{2} R$ - is the unstandardized B coefficient of Rewards

$\varepsilon$ is the error term

\section{Testing relationships between the elements of the rewards and workers' performance}

Rewards was conceptualized with three (4) factor variable (salary, bonuses and fringe benefits and promotion), the confirmatory factor analysis retained all the three indicators. The four factors were subjected to a regression analysis and the results are presented in table 3.2

Table 3.2. Regression of rewards (standardized coefficients)

\begin{tabular}{|c|c|c|c|c|}
\hline & Model 1 & Model 2 & Tol & VIF \\
\hline $\begin{array}{ll}\text { Level } & \text { of } \\
\text { education } & \end{array}$ & .030 & .027 & 1.000 & 1.000 \\
\hline Organizational Re & vards & .474 & 1.000 & 1.000 \\
\hline \multicolumn{5}{|l|}{ Model summary } \\
\hline $\mathrm{R}^{2}$ & 0.001 & 0.225 & & \\
\hline Adj $R^{2}$ & -0.004 & 0.217 & & \\
\hline $\mathrm{R}^{2}$ change & 0.001 & 0.224 & & \\
\hline F-stat & 0.176 & 56.419 & & \\
\hline Sig & 0.676 & .000 & & \\
\hline
\end{tabular}

**. Significant at the 0.01 level (2-tailed). Dependent variable $=$ Workers' Performance, $n=198$ health workers

In model 1, we regress the control variables (Level of education of the employees) on workers' performance and the results show that much as the variables explain $0.01 \%$ of the variance in workers performance, their contribution effect is insignificant. Rewards was added to the equation in model 2 , and the results indicated that rewards explains $22.4 \%$ of the variance in workers performance. Overall, the model explains $21.7 \%$ of the variance in workers performance. We also examine the variance inflation factors (VIFs) in our models to test for multi Collinearity. The highest VIFs were well below the threshold value of 10 suggested by Lo and Field (2018) indicating that multi Collinearity does not pose a problem to the regressions. However, the results do not tell us the particular element of rewards that has a greater effect. If we are to develop training packages to improve rewards and the consequent workers performance, there is need to dissect rewards and identify the areas of emphasis. This led us to conduct a hierarchical regression analysis.

Regression involving the elements of organizational factors

Four models were specified as:

Model 1: $W P=b_{0}+b_{1} E+\varepsilon$

Model 2: $\mathrm{WP}=\mathrm{b}_{0}+\mathrm{b}_{1} \mathrm{~A}+\mathrm{b}_{2} \mathrm{SS}+\varepsilon$

Model 3: $W P=b_{0}+b_{1} A+b_{2} S+b_{3} B F+\varepsilon$

Model 4: $\mathrm{WP}=\mathrm{b}_{0}+\mathrm{b}_{1} \mathrm{~A}+\mathrm{b}_{2} \mathrm{~S}+\mathrm{b}_{3} \mathrm{BF}+\mathrm{b}_{4} \mathrm{P}+\varepsilon$

Model 4: $\mathrm{WP}=\mathrm{b}_{0}+\mathrm{b}_{1} \mathrm{~A}+\mathrm{b}_{2} \mathrm{~S}+\mathrm{b}_{3} \mathrm{BF}+\mathrm{b}_{4} \mathrm{P}+\mathrm{b}_{4} \mathrm{R}+\varepsilon$

Where:

$W P=$ workers performance

$b_{0}$ - is a constant

$b_{1} A$ - is the unstandardised B coefficient of level of education of the health workers

$b_{3} S-$ is the unstandardized $B$ coefficient of Salary

$b_{4} B F-$ is the unstandardized $B$ coefficient of Bonuses and fringe benefits

$b_{5} P-$ is the unstandardized $B$ coefficient of Promotion

$b_{5} R$ - is the unstandardized $B$ coefficient of Recognition

$\varepsilon$ is the error term $\varepsilon$ is the error term 
Table 3.3. Hierarchical Regression Results

\begin{tabular}{llllllll}
\hline & Model 1 & Model 2 & Model 3 & Model 4 & Model 5 & Tol & VIF \\
\hline $\begin{array}{l}\text { Level } \\
\text { education }\end{array}$ & .030 & .002 & .001 & .027 & .016 & .973 & 1.028 \\
$\begin{array}{l}\text { Salary } \\
\begin{array}{l}\text { Bonuses } \\
\text { Fringe }\end{array}\end{array}$ & & $0.514^{* *}$ & $0.507^{* *}$ & $0.531^{* *}$ & $.559^{* *}$ & .881 & 1.135 \\
$\begin{array}{l}\text { benefits } \\
\text { Promotion }\end{array}$ & & & & & & & \\
Recognition & & & .025 & .015 & -.008 & .898 & 1.114 \\
Model summary & & & & & & & \\
$\mathrm{R}^{2}$ & 0.001 & 0.265 & 0.265 & 0.306 & 0.33 & .730 & 1.370 \\
Adj R & -0.004 & 0.257 & 0.254 & 0.292 & .313 & & \\
$\mathrm{R}^{2}$ change & - & $\mathbf{0 . 2 6 4}$ & $\mathbf{0 . 0 0 1}$ & 0.041 & .024 & & \\
F-stat & 0.176 & 69.985 & 0.155 & 11.419 & 6.831 & & \\
Sig & 0.676 & .000 & 0.694 & 0.001 & 0.01 & & \\
\hline
\end{tabular}

**. Significant at the 0.01 level (2-tailed). Dependent variable $=$ Workers' performance, $n=198$ health workers

The results in model 1 show that the control variable do not make a significant contribution in explaining adoption of workers' performance. This suggests that our models are not sensitive to confounding factors and the models are highly plausible. The addition of salary in model 2 reveals an extra contribution effect of $26.4 \%\left(\mathrm{R}^{2} \Delta=.264\right)$ in the variance explained workers' performance and the results indicate that salary is a significant predictor of workers' performance $(\beta=.559, \mathrm{p}=.000)$ implying that a unit increase in salary will result in to 0.559 units increase in workers' performance. The addition of bonuses and fringe benefits in model 3 accounts for the extra $0.01 \%\left(\mathrm{R}^{2} \Delta=.001\right)$ of the variance explained in workers' performance. The model results also show that bonuses and fringe benefits is not a significant predictor of workers' performance $(\beta=-.008, \mathrm{p}>.05)$. The results in model 4 indicate that additional of promotion have significant effect on workers' performance and it explains $4.1 \%\left(\mathrm{R}^{2} \Delta=.041\right)$ of the variations in the workers' performance and the results indicate that a unit increase in promotion of the workers would result in to 0.116 units increase in workers performance $(\beta=-$ $.008, \mathrm{p}<.001)$. Finally the results in model 5 indicate that recognition of the workers explain $2.4 \%\left(\mathrm{R}^{2} \Delta=.024\right)$ and a unit increase in recognition of the workers would result in to 0.182 units increase in workers' performance $(\beta=.182, \mathrm{p}=.000)$. When predictive power and strength of all the four elements are compared, salary has a greater effect on workers' performance. The results also validate hypotheses $1,2,3 \& 4$. Overall, the model explains $31.1 \%$ of the variance in workers' performance. The remaining $68.9 \%$ is catered for by factors not covered in this study.

\section{Discussion}

The results show that rewards and health workers' performance are positively related, and the association is statistically significant $(\mathrm{r}=.474, p=.000)$, thus the stated hypothesis is accepted. This indicates that positive changes in rewards are associated with positive changes in health centre IV workers. This was supported by (Chiang \& Birtch, 2008) who say that the absence of rewards will create an unfriendly environment, thus weakening workers and may cause them to pull out of their jobs. For these reasons, rewards are progressively important because they appeal, maintain and motivate employees to achieve high levels of performance and to stimulate and strengthen the desired behaviour of the workers. Organizations often use financial rewards to avoid employee disappointment and to motivate employees, although it may not be the best motivator for the long term (Mossbarger \& Eddington, 2003).

The results show that all the respondents agree that salary influences their commitment and performance. This was in agreement with (Dorling, 2019) who argued that employees who receive a good pay are likely to be dedicated to the health facilities simply because they would not afford to lose the big salaries. That is why health workers have been involved in strikes or sit down strikes and engaging government in different fora to improve their remunerations. This is an indication that if the government has to deal with health workers 
grievances of remunerations, focus should be premised on salary other than fringe benefits, promotion and recognition. This shows that in an event that a health worker receives adequate salary, there are higher chances that he/she will be committed and will perform better in the absence of other work related benefits.

This was in agreement with Richard (2014) who stated that salaries /amount of salaries given to employees can be well understood as a way of improving performance among employees. This can well be explained in the role of money as a condition to reinforce, an incentive which is capable of satisfying needs, and anxiety reducer that serves to erase feelings of dissatisfaction among employees.

On contrary, some studies (Pandey, 2020),urges that although salary is acknowledged by employees, managers should never use this as a tool to motivate their employees and improve on the performance. Should this occur, there is a transformation that the core principle of the reward would be forgotten. However, the above findings indicate that bonus, fringe benefits and promotion do not play a significant role as far as the health workers performance is concerned. This was also supported by (Magesa \& Leshabari, 2017), who notes that assessment of performance-based financing (PBF) plans in a few settings found bonus payments to be demotivating in cases where the distribution is not transparent, perceived inequitable and perceived unfairness in distribution of resources and decision-making process create no impact on the performance of health workers.

Majority of the respondents supported the idea salary improves performance, they said that the salary enhancement that took place in the country especially for scientists, helped them to improve on their performance though the salary is still not enough. This was supported by (Richard, 2014) who elucidated on the role money as a condition to strengthen an incentive which is capable of satisfying employees' needs and anxiety so as to remove feelings of dissatisfaction so as enhance on the productivity and employee availability.

Majority of respondents supported giving bonus and recognition as a form of reward. This would come as result of performing their duties in time, responding to emergencies in time, attending to patients and be quick at delivering health services from their respective health facilities. This was in agreement with (Willis-Shattuck et al.,2008) who show some seriousness in valuing the workers by providing monetary and non-monetary rewards which consisted of recognition and cash bonuses to workers and these are given separately from the salary and should be fairly allocated based on their performances so as to continue with improved productivity.

\section{VI.CONCLUSION AND RECOMMENDATIONS}

The purpose of this study was to find out the relationship between rewards and performance of health workers' in greater Mbarara district. This was achieved through a questionnaire survey of 200 health workers in health centres IV representing $98 \%$ response rate. Results indicate that rewards are significant predictor of health workers' performance $(\mathrm{r}=.474, p=.000)$.

Overall findings of this study have important implications to both academics, practioners and government. For academics, the results suggested salary is strong predictor of health workers' performance in health centres IV in greater Mbarara district. For health practitioners, they should recognize different remuneration strategies that influence performance positively like; bonus, merit pay and good salary policy. Also they should consider other non-financial rewards like recognition, promotion and career development programs for their health workers.

- For government, the findings are important, when it comes to spending, it should aim at meeting health workers' needs, expectations and desires so as to reduce on labour turnover in health sector.

- This study was limited to health centres IV in greater Mbarara district and it is possible that the results may only be generalized to health sector not only in Uganda but also in other communities of the world.

- This study majorly focused on health centres IV workers and their performance, further research could be carried out in other levels of health care system in Uganda like; private health sector, health centres iii, iii and referral respectively using the same methodology or even using mixed methods methodology.

- There is, therefore, need for more sensitization of health workers on infection control and post-exposure prophylaxis for health workers, Hospital administrations should ensure good access to HIV exposure guidelines for all to health workers. All health workers should be provided with protective gears such as aprons, gloves, goggles, gumboots and overalls during procedures or duty to mitigate the high risk of occupational exposure and transmission to health workers in hospitals attending to these patients. 
- There should be Increasing hospital autonomy offers opportunities to use market pressure and decentralization to improve the efficiency with which hospitals operate, by increasing public participation and promoting internal management reform

- There should be a salary harmonization committee to look at all disparities in health centre and try to bridge the gaps so as to improve performance of health workers.

- Long serving health workers and best performers should always recognize their efforts by honouring them during heroes' day, so that they set an example for other to follow in different health institutions.

\section{REFERENCES}

Anderson Gerbin, D. JC (1984) The effect of sampling error on convergence, improper solutions, and goodness of fit indices for maximum likelihood confirmatory factor analysis. Psychometrika, 49, 155-173.

ann Richey, L. (2010). Reproductive Health, Family Planning, and HIV/AIDS: Dangers of (Dis) Integration in Tanzania and Uganda. Markets and Malthus: Population, Gender and Health in Neo-liberal Times, 265.

Bagozzi, R. P., \& Yi, Y. (1988). On the evaluation of structural equation models. Journal of the academy of marketing science, 16(1), 74-94.

Bhattacherjee, A. (2012). Social science research: Principles, methods, and practices.

Chiang, F. F., \& Birtch, T. A. (2008). Achieving task and extra-task-related behaviors: A case of gender and position differences in the perceived role of rewards in the hotel industry. International Journal of Hospitality Management, 27(4), 491-503.

Churchill, G., \& Iacobucci, D. (2004). Marketing research: Methodological foundations Thomson Corporation. South Western, Ohio. Dorling, D. (2019). Inequality and the 1\%: Verso.

González-Pier, E., Gutiérrez-Delgado, C., Stevens, G., Barraza-Lloréns, M., Porras-Condey, R., Carvalho, N., ... Casey, A. (2006). Priority setting for health interventions in Mexico's System of Social Protection in Health. The Lancet, 368(9547), 16081618.

Harris, L. R., \& Brown, G. T. (2010). Mixing interview and questionnaire methods: Practical problems in aligning data.

Health, M. o. (2016). Cancer: New Registrations and Deaths 2013: Ministry of Health Wellington.

Health monitoring unit Report (2008/2004) State house, Kampala Uganda

Kazo district Abstract Report, 2018/2019), Kazo District

Koo, L. K., \& Expert, K. (2008). President's Office Public Service Management.

Kutzin, J. (2001). A descriptive framework for country-level analysis of health care financing arrangements. Health policy, 56(3), 171-204.

Larsson, E. C. (2012). Missed opportunities: prevention of mother-to-child transmission of HIV in Uganda: Inst för folkhälsovetenskap/Dept of Public Health Sciences.

Lo, B., \& Field, M. (2018). Conflict of interest in medical research, education, and practice. 2009. Washington, DC: Institute of Medicine.

Magesa, D. J., \& Leshabari, M. (2017). Perceived barriers to access available health services among men who have sex with men in Dar es Salaam, Tanzania. Tanzania Journal of Health Research, 19(4).

Mbarara district Abstract Report (2017/2018), Mbarara District.

Ministry of Health Uganda: Health Sector Strategic Plan III: 2010/11 2014/15.Kamp Government of Uganda; 2010.

http://www.health.go.ug/docs/HSSP_III_2010.pdf.

Mossbarger, M., \& Eddington, J. (2003). Methods for motivating employees. Weber State University. 
Mukyala, B. (2018). Factors Affecting Timing Of 1st Antenatal Care Among Mothers At Antenatal Clinic In Bukigai Health Centre Iii Bududa District. International Health Sciences University.

Nunnally, J. C. (1982). Reliability of measurement. Encyclopedia of educational research, 4.

Okech, T. C. (2014). Analytical review of health care reforms in Uganda and its implication on health equity.

Organization, W. H. (2000). The world health report 2000: health systems: improving performance: World Health Organization. Pandey, N. (2020). Critical Evaluation of Most Valued Non-Monetary Rewards Employees. Our Heritage, 68(30), 8718-8728.

Peters, R. K. (2017). Reform and growth: Evaluating the World Bank experience: Routledge.

Witter, S., Bertone, M. P., Namakula, J., Chandiwana, P., Chirwa, Y., Ssennyonjo, A., \& Ssengooba, F. (2019). (How) does RBF strengthen strategic purchasing of health care? Comparing the experience of Uganda, Zimbabwe and the Democratic Republic of the Congo. Global health research and policy, 4(1), 3. 